\title{
Globalization and Innovation: Development Factors in Subnational Governments in Mexico: The Case of the State of San Luis Potosi*
}

\author{
Mario E. Ibarra Cortés \\ Universidad Autonoma de San Luis Potosi, San Luís Potosí, México \\ Erika García Méndez \\ Universidad Nacional Autónoma de México, Distrito Federal, México \\ Universidad Autonoma de San Luis Potosi, San Luís Potosí, México
}

\begin{abstract}
The main idea of this paper is that the role of the local governments as decision makers, as well as policies generators, has been discussed in recent years under different subjects, considering that the trendy practices and the participation of different governmental and non-governmental actors are the cause of development in some matters related to the design and implementation of successful public policies. These new forms-also known as innovation-are shown in the re-design of the administrative structures, the interactive networks with citizens and the change of the institutional frames of government into a new context generating collaborating programs, involving diverse areas, working, designing, and implementing policies which involve multiple actors, shared responsibilities, and searching for local development under innovative strategies. For that reason, this paper's objective is to try to understand how local governments are generating new forms of working, taking as main innovation reference the participation of diverse actors and the learning processes generated through these experiences. It analyzes from a qualitative perspective four successful Mexican local cases considered as good practices.
\end{abstract}

Keywords: local government, innovation, governance, implementation, public policy, public administration.

\section{Local Governments in Mexico}

In recent years the role of the subnational governments as making decisions entities and policies generators has been discussed from different fields. The academy has been giving a boost thanks to the contributions leaded by the "Centro de Investigación y Docencia Economica” (CIDE), which during the last 10 years has awarded and documented the successful practices of the municipalities in our country, making a

\footnotetext{
* We appreciate the financial support provided by the Ministry of Research and Graduate Studies of the University of San Luis Potosí using the Support Fund for Research (FAI).

Mario E. Ibarra Cortés, Ph.D., Full time Professor of the Graduate Studies Department of the Faculty of Accounting and Administration, Universidad Autonoma de San Luis Potosi.

Erika García Méndez, Master degree, Doctorate student of Political and Social Sciences, Universidad Nacional Autónoma de México; Invited Professor of the Graduate Studies Department of the Faculty of Accounting and Administration, Universidad Autonoma de San Luis Potosi.

Correspondence concerning this article should be addressed to Dr. Mario Eduardo Ibarra Cortés, Cerrada de la Paz No. 126 Fracc. La Paz C.P. 78030, México. E-mail: meic2003@hotmail.com.
} 
difference as detonating developing factors in the area of design and public politics implementation.

The government has implemented several policies with the participation of the Federal, State, Municipal governments as well as different groups of the civil society which are organized to try to mitigate complex problems from local strategies development. In this sense they try to generate optimal solutions that contribute to decrease the lack of opportunities and inequality, generating self-employment schemes in medium and small companies, as well as the occupation of vulnerable groups in different tasks.

Thus, the new intervention forms in the different governmental areas, promote different collaboration, participation and coordination schemes, the implementation of strategies to generate working alternatives as well as a learning in the locations to solve complex social and economic problems and implement new technologies that promote development and progress through several actions which complement the complexity of the management governmental system.

These new forms are appointed as innovation and are manifested in the redesign of administrative structures, of the interactive mechanisms within citizenship and the institutional government framework into a new stage (Cabrero, 2002, p. 22), generating governance schemes whose effects are new participation forms, cooperation, intersectoral work, design and implementation of policies that involve multiple actors.

In that under this assignment considers the contributions of two previous ${ }^{1}$ assignments which initiated as part of a deeper investigation that searches to understand, to make evident as well as to document how local governments in the State of San Luis Potosi are generating new forms of working, taking as the greatest predictor of the innovation the participation of different nontraditional actors in the management of the locations and the learning which is generated by these experiences.

The assignment is divided into three parts: In the first part contributions related to innovation of local governments, changing schemes as well as local management and its evolution to more participatory developing models are established; In the second part three successful innovation local cases in the state of San Luis Potosí are analyzed; Finally a reflection for government innovation and learning experiences as well as the whole society will be made.

\section{Background}

To say Mayntz (1993), the failures in which governments incur question the stability and the potential of the governmental actors to heed the most important problems and develop feasible and stable scenarios for individuals. In this sense three main debate areas have been distinguished: the regulation, development, and welfare, which have been identified as weak points or in crisis in the last decades of the 21st century. Therefore, to address these effects are instruments of government seek alternatives to traditional and innovative forms of interaction and participation.

These instruments, are conceptualized to develop theoretical frameworks that account for the development of a specific phenomenon, therefore, is in this concept where it speaks of "governance", a term that has taken a lot of meanings in different contexts, and has generally been conceived as an academic construct that gives meaning and understanding to the number of new practices implemented to achieve greater benefits from the multi-management policy through the different actors involved in decision making, each with a specific weight.

\footnotetext{
${ }^{1}$ All of the above were taken from the Government and Management Award published by the CIDE annually.
} 
According to Rhodes (1996), governance is defined from different perspectives ${ }^{2}$ and they may find some features in common; in this particular case, it has been talked about governance when considering society participation in decision making, when the lines between public and private sector are not clear, when a group of actors are conceived as a network that acts together and shares objectives and responsibilities that lead to the welfare of society. ${ }^{3}$

In this sense, Krahmann (2003) agrees that this concept is manifested in different forms and the proposal places the government and governance as ideal concepts polarized to understand how decision making has evolved, which are the implications of what happens at different levels and how these problems can be used as reference to solve other problems in different sectors and levels.

Jordan, Wurzel, and Zito (2005) argue that governance with a minimum of state government intervention does not prevail in the conduct of modern societies. They argue that governance and government can be placed on a continuum where the two concepts are polarized, and far from disappearing or completely dulled with each other, complement, and that require different tools and levels of intervention by institutions. The forms of intervention are those that vary, adopting new trends and the involvement of other actors configured a new form of society these relationships with the state and its regulation.

Following Payne (2005), the state remains important role in decision-making or some condition, in some cases which promotes the study of how these changes determine new orders in the relations of individuals to their environment and groups which interacts. For Davies (2002), meanwhile, governance focuses on a greater number of forms of market interaction, society, hierarchies and networks. Not conceive the concept of governance where the state becomes one more of the actors, because, believe that the tendency of government in public policy is centralized, therefore, the role of government is very important and the use of hierarchical structures predominate.

To understand these processes from governance it must been taken into account two factors of overriding importance: The first is that context matters, since there is no single form of governance due to cultural differences and system of government that can occur in different countries or states the same country or subnational entity of a state; and Secondly, that the degree of democratization and the process has been developed to achieve the same range and determines the structures and behaviors of a specific system (Porras, 2007).

Mexico has been generating changes in recent years in the way of doing politics and to propose viable solutions to the problems the country faces. These new forms can be analyzed from governance, as the involvement of nongovernmental actors, the lack of clarity in the division of powers, resources and participation of those involved, the tendency to decentralize federal functions to local governments, and the independence of these to perform their functions led us to form new structures and achieve a more participatory setting (Porras, 2007). Innovation in processes and far-reaching changes can be seen, therefore, from the local level of government which has led to successful programs that influence the decision to carry out its functions more effectively and efficiently (Guarneros-Meza, 2007).

\footnotetext{
${ }^{2}$ New public management, corporate governance, good governance, governance and international interdependencies as a socio-cybernetic system, such as new political economy network.

3 The concept of governance has a load of autonomy and independence implied, actors or entities tend to vertical structures and are increasingly less regulated by central organizations. Their participation is critical to the proper functioning of government, society and state, and to deal with the complexity of modern societies.
} 


\section{Statement: Innovation in Local Management}

Until recent years, sub-national governments in the case of Mexico are at the municipal level, they had no great significance in the political, social, and economic issues of the country, as the functions and resources had been highly centralized. In 1980, the figure of the municipal level began to affect a number of reforms to Article 115 of the Constitution, in which resources and decision-making were decentralized from the federation. This situation can be seen from a positive perspective and many statements have been linked with the knowledge that each municipality known for its own immediate needs, resources and natural wealth that allows programs to boost the economy under regional and local development and the autonomy it enjoys in certain areas and on the other hand, is still limited especially in a situation of dependency and financial autonomy that is reflected in the decisions, conditional.

Giving too much power of decision to the municipality would have the ability to recognize human, material, and technical resources to achieve the goals set in terms of solving the political, economic, and societal issues. It also recognizes that municipalities in Mexico are characteristic of a great heterogeneity in terms of culture, traditions, resources, and opportunities, thus giving too demands for autonomy might not be as beneficial as previously proposed.

However with the resources they have and the participation of various actors in the game of decisions it has been seen that the public begins to demand more efficient and democratic means assigning new roles for institutions to achieve the goals they have set. As a matter of Cabrera (2002, p. 3), there has been observed at least four types of innovative strategies: The first refers to a new kind of leadership, which sets aside the rigid hierarchical structures and promotes the formation of teams composed of government and citizenship; the second perceived the establishment of mechanisms that promote ongoing interaction between governmental and nongovernmental; the third identifies intergovernmental management mechanisms; and finally observe strategies that lead to the modernization with respect to the management administration.

In this regard, it is referred to the first strategy of the classification given above, to conceive it as a form of governance perspective from which new forms of governance designed to act as an intervention that is no longer unilateral, to include various actors in the political game (Kooiman, 1993, p. 4) and find efficient and legitimate responses to the resolution of social, political, and economic, through cooperation and collaboration between them, it refers to arrangements in which the actors involved interact and are defined from the difficulty in identifying the boundaries in what corresponds to the act and the responsibilities of each of them (Kooiman, 2000, p. 140).

These new forms are characterized by greater diffusion of power, usually shown with the addition of non-governmental actors in processes that were once exclusive to the government, thus the presence of local actors are autonomous and wield that power has increased the need to develop new leadership, based on more communicative governments and policy convergence (Porras, 2007, p. 43).

\section{Research Design: Local Government Innovation in the State of San Luis Potosi}

This section presents three innovative practices of local governments in the State of San Luis Potosi: The first corresponds to a Productive Restructuring Programme in the Ejido El Peyote in the Municipality of Guadalcázar; the second to the creation of the Institute for Quarry in Escalerillas community, located in the municipality of San Luis Potosi; and finally, the Personal Security Program School in the same municipality. 


\section{Restructuring Production in the Field: The Case of Ejido El Peyote in the Municipality of Guadalcázar}

This first example of innovation allows us to visualize different new alternatives for economic development in rural communities that have historically been marginalized and now to the synergy of the different levels of government and actors involved can observe new participation schemes such as the Guadalcázar experience ${ }^{4}$ that is a municipality belonging to the State of San Luis Potosi, which is located in the altiplano region and is made up of mountainous terrain and dry desert climate, has a land area of $4,244.30 \mathrm{~km}^{2}$, which represents $6.76 \%$ of the state, most of its surface is covered with desert scrub, so that agricultural production is consumption.

Its population, according to the census of 2000 is 25,482 people, which represents $1.10 \%$ of total state, it is noteworthy that the population decreased over 1990 to $6.11 \%$. In general, this is a very poor area, with very limited job opportunities, poorly paid, and hard for agriculture by the limited water resources.

The Productive Restructuring Programme was a response to the lack of agricultural productivity due to the scarcity of water to grow corn and beans. The aim of this was encouraging, depending on the ecological, sustainable development in regions with recurrent drought, boosting the productive reconversion towards sustainable production systems as an alternative to the better use of local natural resources and changing patterns of production high risk, productive models in line with regional characteristics with susceptibility to be replicated.

The activity they were looking for developing would be cattle farming by planting buffelgrass, which would serve as food for livestock and would provide maintenance to the locals self-generating source long-term employment through training that would help the better use of natural resources in the area.

In this scenario, a group of landowners in 1990, with support from one of the senators of the state and local government, presented to the Ministry of Agriculture and Rural Development's proposal for a comprehensive program of conversion of agricultural areas with livestock purposes; of Thus the presence of local actors that are autonomous increased the need for new leadership systems based on more communicative actions of government and policy convergence (Porras, 2007, p. 43). In that year laid the bases of the program with the planting of the first 350 acres of buffelgrass. Thus in the Ejido El Peyote was a network that included governmental and nongovernmental organizations throughout the time was changing and integrating more participants from the three spheres of government and nongovernment composed of the landowners. In 1994, the company named May 25 Rural Production Society of Ejido Peyote was integrated by 77 producers, initially enjoying the support of the Shared Risk Trust (FIRCO) and Alliance for the Countryside in 1997 Guadalcazar Municipal Government was more interested in the program to become the partner of the actors involved, having the involvement of other government actors.

A third time the Society of Rural Production had fragmented to form two predominant groups in 2005, two years later suffered another breakdown and formed a third group of producers. This network is composed by the federal level with the Secretary of Agriculture, Livestock, Rural Development, Fisheries and Food (SAGARPA) through Support Services for Agricultural Marketing Program for the Direct Rural Support (PROCAMPO) and the Agency for Agribusiness Promoter by the Shared Risk Trust; the state level involving the Ministry of Agriculture and Water Resources (SEDARH) and the Department of Social and Regional

\footnotetext{
${ }^{4}$ For deepening it has been recommended reading Santos, Joseph; Mario Ibarra, "Restructuring production in the field". The case of the ejido El Peyote, Guadalcazar, San Luis Potosi in "Innovation in local government: An overview of municipal experiences in Mexico” (pp. 209-223), National Center for Municipal Development, National Institute for Federalism and Municipal Development, the Center for Economic Research and Teaching (CIDE), and Ford Foundation, Mexico, 2002.
} 
Development (SEDESORE), the Municipal area joined the Coordination of Agricultural Development of the Municipality of Guadalcázar and nongovernmental actor are different associations of producers in the community.

The relationship between these actors is of mutual dependence, as each of them brings different resources, FIRCO paid labor for planting of grass, the Rural Alliance, provides a percentage of total investment for electric fences and construction of drinking fountains, SEDARH supports the technical staff and, finally, the central actor is the municipal government, through the Coordination of Agricultural Development, provides the seed, organizes producers, provides advice, technical assistance, training, prevention and innovation, manages the resources, contributes to the promotion of livestock marketing and is also responsible for implementing and monitoring the performance of the resources given to the program, producers also focused as a central player to the government, implementing new technologies and achieving position the municipality as innovative and legitimate process to the federal government.

With the implementation of the program they could have many benefits, the resources provided and produced increased earnings, PROCAMPO programs for 2007 and "Crédito a la Palabra" gave an annual basis and 400 to 829 pesos per hectare, as the cost of maintenance of grasslands is only to give them proper care, the resources granted become additional income for landowners. Other evidence is that planting buffelgrass reduced the amount of land needed to feed an animal, 17 to three acres per animal unit, thus the ability to feed livestock has increased fivefold.

Producers have quality animals, so their profits and market position has improved, now they have the ability to sell animals as stallions to other producers, in addition to marketing its products under high standards of quality. Productivity has grown enormously, the conversion program in the "Ejido El Peyote" has a little more than 13 years in operation since 1997, however, only operated for six years on 350 acres with 50 head of cattle and with 77 charter members. By 2007, 787 hectares had been built, 411 and 159 head of cattle producers. With these achievements, the program operates in 90 percent of "ejido" lands, and has become an example of development for the altiplano region of Potosi and nationally.

The "Ejido El Peyote" program has become a central actor and political weight in the municipality, an example is that the municipal authorities, under the high degree of organization of the "ejidatarios" gave for the management 2003-2006, various positions in the municipal administration, among which the treasury of the municipality. For state officials, the program has allowed state and local governments to obtain additional resources to support this activity, and greater recognition and legitimacy in the results that gestures produce.

Being the Municipality of Guadalcázar a high marginalized area, it could be said that the "Ejido El Peyote" has overcome some of the shortcomings of the facing, there are citizens who live better prepared with necessary services such as drainage, electricity, and education.

\section{The Creation of the Institute of Quarry in the Community of Escalerillas}

The second case documented for this paper is the community of "Escalerillas" ${ }^{5}$ which is located $15 \mathrm{~km}$ from the municipal capital of San Luis Potosi and is comprised of six small communities: "Pozuelos", "La Maroma”, "Escalerillas”, “Casa Blanca”, "Mesa de los Conejos”, and “Colonia Insurgentes”. These

\footnotetext{
${ }^{5}$ In order to deepen it has been recommended: Ibarra, Mario Cortes Santos, Jose, "Local socioeconomic development: The case of the Institute of the quarry in San Luis Potosi” in “Town and governance: Momentum of local experiences in Mexico" (pp. 186-196). Franco Program-Mexican Municipal Cooperation and the Center for Economic Research and Teaching (CIDE), and Ford Foundation, Mexico, 2006.
} 
communities are at the edge of highway 147, which connects to Guadalajara. Its population in 2003 was 6,066 people, according to the study of Social Welfare, Bureau for Economic Development of the municipal government, it has a high degree of marginalization. This community has a long tradition of craft production of quarry, which represents one of its main economic activities. This activity is possible because the area is located in a region where unexploited veins of quarry at full capacity exist, this operation is not fully due to difficult access and the use of traditional techniques of extraction-dynamite-explosion, also to diversify the production of quarry, this is brought from Aguascalientes, Michoacán, among other states.

The activity of carved in stone has decreased in recent years, a situation which is mainly due to unprofitable activity, migration of youth to the state capital and the United States, as well as the concentration of the activity of the quarry in a few people who have had the financial capacity to meet domestic demand and international levels. In view of this situation are fewer and fewer people engaged in this activity. For this situation, the artisans who are dedicated to work the quarry have declined considerably, further that such product has great market potential internal and external but not served by the lack of infrastructure to increase production and the lack of product promotion. These three situations can be considered as the problems it seeks to address the municipal government by creating the Institute of the quarry.

To achieve this general objective, the municipal government elected for the period 2004-2006, in January 2004 made the following specific objectives: (1) Conduct the training of new artisans and teachers at work in the quarry in order to promote education, professional training, and updating work processes; (2) Provide development opportunities for both men and women, in order to achieve employability and gender equity in the community; (3) Improve the living conditions of the population of the community of Escalerillas; (4) Promote economic development in the region, offered to attendees local hiring opportunities and at the same time, business creation; and (5) Sell the quarry efficiently produced in the body so that it can be marketed domestically and internationally.

With the creation of the Institute it was pretended to rescue the quarry office of the quarry, benefiting more than 325 people from 65 homes are linked to this activity. Likewise, it was intended that young people regained interest in the quarry work, by training a new generation, trained staff giving the nearly 16 workshops that are in the community.

To address the problem and carry out the objectives, the municipal government, through the Economic Development Division designed a strategy, presented in three stages: (1) Diagnosis and community awareness; (2) Construction of infrastructure and operation of the institute; and (3) Promotion and marketing of the quarry. To cover the first phase, staff from the Directorate of Economic Development were conducted a census in the community of Escalerillas in order to identify those totally dedicated to the mining and quarry work. From the data obtained from this census a diagnostic of the use of the quarry was made, with the support of the community surveys which were used to diagnose people welfare. Likewise, with the support of the Council of Mineral Resources of the State Government that conducted a study of the area, unexploited quarry banks were located and quantified. As part of the first stage, the producers were organized to participate in courses that the Institute would impart.

In the second stage, talking about infrastructure construction, first, in coordination with the State Highway Board, the road which leads to the quarry banks, which are located about eight kilometers from the community, was extended and maintained. The construction budget comes from three levels of government, where as the main contributors are SEDESOL HABITAT through the program, the Federal Ministry of Economy, the 
Ministry of Economic Development, State Government and the City of San Luis Potosi through the Economic Development Authority, the latter being in charge of following up and continuing the program, the total investment, once the building is finished is expected to be $\$ 2,731,044.00$.

The land $\left(500 \mathrm{~m}^{2}\right)$ for September 2005 was in a second stage of construction where there is already a room about $32 \mathrm{~m}^{2}$ and an area where it will be the workshop and a rolling mill is provided by the city, but it is remarkable that much more needs to be done, as would be the floor of the workshop area, roofing sheets through the same area, water system (without which it is impossible to use the mill, as it requires water for cutting stone), the water recycling system used in cutting through sinks, fixing the outside of the school and the acquisition of a water tank for storing water. In the third stage, operation of the Institute, instructor was hired, with contracts renewable every six months, who depends directly from the Department of Economic Development, who reports on a monthly basis his activities. At this stage courses for women and men are imparted, the program is taught in modules quarterly. Training is provided to men and women separately due to the orientation of the needs of each. In summary, the Institute of Quarry breaks inertia, as amended through local government action, the traditional processes of governance, as it involves government agencies in the three levels of government and organized working people of the quarry, by means of which the design and operation of local public policy in its first two stages was possible.

In the field of intergovernmental relations, networks built by the institute through municipal government interacted as well as implementing actions that allowed more scope and where the citizens offered their service and community work organization to legitimize this new way of managing local public affairs. Traditional forms of governance arrangements were modified with this form of local management through a horizontal and close relationship to the community, showing commitment and transparency of government action.

\section{The Program of School Safety Personnel in the Municipality of San Luis Potosi}

Now the third program exposed is the program School Safety Staff $(\mathrm{PES})^{6}$ called "Children of yesterday working on the men of tomorrow". The program is to provide and improve road safety for students, teachers, parents, and the general public when in and out of schools (kindergartens, primary, and secondary), mainly from the city center. Since its inception the program seeks to address two central issues: firstly provide certainty for schools in the urban area of the municipality and, on the other hand, incorporating the retired population in productive activities. The program operates with the intervention of federal government agencies, state and municipal, although the central responsibility is the General Direction of Municipal Public Security. The initiative for this program originated in 1998 during the 1997-2000 municipal administration, which led Alejandro Zapata Perogordo as mayor, from the beginning had a double objective: To satisfy demand and road safety near schools, especially in times of entry and exit of students, and improve the living conditions of pensioners. The 2000-2003 administration headed by Marcelo de los Santos Fraga, the program incorporates and consolidates, in this period increased the participation of parents, teachers, and students in the program, to the extent that the participation of the municipality is coordinator and manager of the actions of those involved.

The objectives of the program to date are providing security and a better road to the students, teachers, parents, and the general public at the time of entry and exit of schools, inviting mature age people who are retired or pensioners, to return to the productive sector, in order to control the speed of motorists in school

${ }^{6}$ To deepen the reading program it has been recommended Santos, Joseph, and Ibarra, Cortes, Mario; The Personnel Security Program School: "Children of yesterday working on the men of tomorrow" in Municipal Agenda, Volume 1, Number 5, Mexico 2002. 
zones, speed up the ascent and descent of students, eliminate double-parked vehicles, detect risk situations close to the school to suggest devices and operations.

One of the central themes of the program are PSE's, those are the elements of school safety, retirees or pensioners aged between 45 and 60, with minimum education of high school and no criminal record. To be hired the applicant must pass a series of tests (physical, psychometric, and medical) to conclude successfully this stage then moves to a process of training in the police academy and city traffic, where they teach subjects related to monitoring and roads. The PSE's service is constantly updated and fed back through working meetings held once a week with management and program coordination.

The PSE's receive a bonus of $\$ 1,200$ a month for four hours worked daily Monday through Friday. The times in which they remain laboring differ from each other depending on which school assigned to enter entry-half hour before and half an hour after the departure of students. Additionally, PSE's tours conducted supervisory to detect and prevent possible circumstances that endanger the safety of students. The PSE's are supported by traffic agents, who organized motorcycle routes in monitoring and support in case a motorist violates the traffic rules and warrants a penalty. To receive the benefits of the School Safety Program, educational institutions must make a written request, where sets the monetary amount they are willing to provide or justification of the institution requires a subsidy to operate the program, Coordination of PSE makes an assessment of the request, performing a field study in the area, is reported in case it is approved to the school and a series of meetings with parents, ${ }^{7}$ school officials and students are carried out, to raise awareness of the benefits of the program and the importance of collaboration of all involved.

As resources for the program, they are provided by two instances, the municipal budget and the educational centers, which have increased continuously, mainly contributed by the beneficiaries. Government agencies involved in the program are: The Delegation of the Institute of Security and Social Services for State Workers (ISSSTE), Mexican Social Security Institute (IMSS), the National Institute of Older Persons (INPAM), the Institute of national Aging (INSEN) of the Federal Government; Ministry of Education of the State Government (SEGE), the State Educational System Regular (SEER) of the State Government, the Municipal Public Security Bureau (DGSPM) and schools benefited from the program. Ministry of Education of the State Government (SEGE), the State Educational System Regular (SEER) of the State Government, the Municipal Public Security Bureau (DGSPM) and schools benefited from the program.

The participation of the ISSSTE and IMSS is to sign a free collaboration agreement to the program for the security elements (PSE's), so retirees or pensioners do not lose their rights by entering into gainful employment. The INSEN and IMPAM serve as a link between the program and applicants to join it. State government through the Ministry of Education and the SEER facilitate program implementation and coordination of the security program and schools. The DGSPM organizes the institutions involved, manages and is responsible for implementing and monitoring the performance of resources and the proper functioning and achievement of the objectives for which the program was created.

The focus of school performance is the institutions benefited, which are organized by associations of parents to provide financial resources and monitoring and evaluating the program at each school. The PSE occupies a significant place on the agenda of the municipal government, as this has allowed it to address the problem of roads in school zones of increased congestion, and increase security in them.

\footnotetext{
${ }^{7}$ Santos Jose, and Ibarra, Cortes, Mario; Citizen Participation in Municipal Management: Program School Safety staff of the municipality, the Local Government Innovation Journal, Volume 2, Number 3, Mexico 2002.
} 
It has also contributed in various ways: (1) has increased the living standards of retirees and pensioners; (2) has provided viable solutions at low cost to everyday problems of the urban municipalities; (3) has generated continuity in municipal programs which is made possible if the central axis thereof are the users; (4) has prompted the collective decisions that contribute to the operation of successful and legitimate programs; (5) has maintained a record of zero accidents around schools and decreased unlawful acts and traffic problems; and (6) the satisfaction of users has increased significantly.

In summary, the PSE has made significant achievements, which make it a successful program, especially considering its low cost and high social impact. The key to success of this program is in planning the program, ongoing communication among those involved, the continuity that was given from one management to another and the involvement of beneficiaries.

In which it corresponds to the teachings of municipal management in Mexico, it can be said that: (1) it involves the beneficiaries as the core of institutionalization of municipal programs; (2) with obvious results it is possible that beneficiaries bear the cost of operation of municipal programs; (3) without major investments, but creativity it is possible to solve everyday problems of large cities; and (4) implement public actions organized ensure the credibility of municipal public policies.

\section{Conclusions}

Innovations in policy processes have changed at the local level of government, initiatives are perceived and the participation of new actors in the political context of local governments in Mexico is perceived. In this sense, there had been identified patterns of cooperation and inclusion of a greater number of players in decision-making and resource management to create new forms of production, socialization, and learning opportunities.

Decentralization, political change and the existence of a troubled society have increased the complexity and uncertainty in the management of public organizations, so the main challenge for governments is to create conditions for innovation, for which they need new mechanisms to regulate their functioning. In this sense, innovation must be understood as an irreplaceable necessity of the new form of government, adopting a more participative structure, unlike the hierarchical model, where the municipal administration exercised centralized control over the various actors in society. In the new governance none of the actors involved in public affairs is above the other, so that the organizational forms of local government shall be characterized by the existence of a horizontal structure with autonomous actors and the adoption of organizational networks for the design and operation of public policy.

The operation of municipal governments based on an institutional reform, requires autonomous actors willing to compromise, although provisional, enabling the development and operation of public policy. This requires the adoption of network-based organizational form, which requires a series of structural conditions and institutional preconditions. The most general condition to develop is that power must be dispersed in society, but not as fragmented and inefficient. The political authorities have to be strong, but not omnipotent. They have to be democratically legitimated, so that it may be considered elected representatives reflect the interests of all social groups. In other words, the political authorities must be able to be accepted, in general, as interlocutors between the state and society. It is also necessary that the political authorities manage sufficient resources to carry out the decisions made, which must be sufficiently diversified to meet the different needs of society.

The municipal government performance based on interacting organizations also requires a strong civil 
society, functionally differentiated and well organized. Society is a community of citizens, individuals who enjoy equality before the law and a set of fundamental rights and whose freedom to pursue their goals is limited only by the equal rights of others. A society can not exist where there is great social inequality, it is incompatible with a horizontal government structure. To have a functioning local government network, the society must have functionally differentiated subsystems, where specific organizations carry out specialized functions. There has to be organized actors representing different social interests. These organizations should possess relative autonomy, that is, that should not be politically controlled, as in the authoritarian state. In particular, the organizations of social interests must be sufficiently autonomous and able to negotiate with opposing interests and local government agencies. But also between different social groups and organizations must be at least a minimum sense of ownership and responsibility to the whole that is to say there must be a common identity.

In all three cases studied, municipality experienced changes in its forms of performance and managed to improve its management through these programs; more responsible and participatory roles were taken as well as collaboration and learning of those involved, who in turn took a central role in the development of programs; transcendental issues were added to the government agenda, designing, and implementing public policies around several factors.

The innovation poses the need to transform municipal governments, exceeding the administrative reform strategy, which so far has dominated. The key is to make it a priority to change the regulatory mechanisms that determine the structure and operation of municipal public administration. The work is to find the relevant rules and standards that allow the plurality, transparency, and efficiency. Therefore, experiences like those presented should be considered for implementation by other local governments as a means to institutionalize patterns of cooperation between government and society and to increase confidence in the government through the results to reflect in programs that are implemented to improve the living conditions of the population and generate scenarios of social development.

\section{References}

Cabrero, M. E. (2002). The award local governance and management in Mexico: A mechanism for institutionalizing innovation in local government. Proceedings from VII International Congress of CLAD on State Reform and Public Administration, Lisbon, Portugal.

Cabrero, M. E., \& Carrera, A. (2008). Local innovation in Latin America. Mexico: CIDE.

Cabrero, M. E., \& Peña, A. J. (2008). New public management instruments to build a new public governance: The case of local governments in Mexico. Public management in North America, El Colegio de Mexico, Institute of Public Administration of Nuevo Leon, Mexico.

Davies, J. S. (2002). The governance of urban regeneration: A critique of the “Governing without Government' thesis”. Public Administration, 80(2), 301-322.

Guarneros-Meza, V. (2007). Urban governance and participation in central Mexico. Development, 50(1), 104-109.

Ibarra, M., \& Santos, J. (2006). Local socioeconomic development: The case of the institute of the quarry in San Luis Potosi in town and governance: Momentum of local experiences in Mexico (pp. 186-196). Franco Program-Mexican Municipal Cooperation and the Center for Economic Research and Teaching (CIDE), and Ford Foundation, Mexico.

Jordan, A., Wurzel, R. K. W., \& Zito, A. (2005). The rise of 'new' policy instruments in comparative perspective: Has governance eclipsed government? Political Studies, 53, 477-496.

Kooiman, J. (1993). Governance and governability: Using complexity, dynamics and diversity. In J. Kooiman (Ed.), Modern governance: New government-society interactions. Londres: Sage.

Kooiman, J. (2000). Societal governance: Levels, models and orders of social-political interaction. In J. Pierre (Ed.), Debating governance: Authority, steering and democracy. Oxford: Oxford University Press. 
Krahmann, E. (2003). National, regional, and global governance: One phenomenon or many? Global Governance, 9, 323-346.

Mayntz, R. (1993). Governing failures and the problem of governability: Some comments on a theoretical paradigm. In J. Kooiman (Ed.), Modern governance: New government-society interactions. Londres: Sage.

Payne, L. (2005). The discourse of development in school governance. Educational Research, 15, 57-59.

Porras, F. (2007). Rethinking local governance: Hierarchies and networks in Mexican cities. European Review of Latin American and Caribbean Studies, 83, 43-59.

Rhodes, R. A. W. (1996). The new governance: Governing without government. Political Studies, XLIV, 652-667.

Santos, J., \& Ibarra, M. (2002). Citizen participation in municipal management: Program school safety staff of the municipality. The Local Government Innovation Journal, 2(3), 209-223.

Santos, J., \& Ibarra, M. (2002). Restructuring production in the field: The case of the ejido El Peyote, Guadalcazar, San Luis Potosi (pp. 209-223). National Center for Municipal Development, National Institute for Federalism and Municipal Development, the Center for Economic Research and Teaching (CIDE), and Ford Foundation, Mexico.

Santos, J., \& Ibarra, M. (2003). Academic safety personnel in San Luis Potosi in local governments working: A journey through municipal programs that work (pp. 491-503). National Center for Municipal Development, National Institute for Federalism and Municipal Development, the Center for Economic Research and Teaching (CIDE), and Ford Foundation, Mexico. 